\title{
EL COMERCIO DE IMÁGENES DEVOCIONALES CON AMÉRICA Y LA PRODUCCIÓN SERIADA DE LOS TALLERES ESCULTORICOS SEVILLANOS.
}

\author{
JESÚS PORRES BENAVIDES \\ CES Felipe II. Aranjuez
}

\begin{abstract}
Resumen
Es bien conocida la relación comercial que tuvo Sevilla con América. Dicha relación se extrapoló también al ámbito artístico. Sevilla durante el siglo XVI tuvo numerosos talleres escultóricos que en gran medida surtieron de imágenes devocionales al nuevo mundo. Algunas de estas obras (esculturas, relieves y retablos) se tallaban ex profeso para encargos en dichas tierras, otras se realizaban para venderlas allí y otras se hicieron en serie mediante moldes y se reproducían en plomo o terracota.
\end{abstract}

\section{Palabras clave}

Sevilla, América, siglo XVI, reproducción de esculturas, talleres.

\section{THE COMMERCE OF DEVOTIONAL IMAGES WITH AMERICA AND SERIAL PRODUCTION OF THE SEVILLIAN SCULPTURE WORKSHOPS,}

\section{Abstract}

It is well known the commercial relationship that existed between Seville and America during the XVIth century which also applied to the artistic market. During this century Seville saw the flourishing of a number of workshops that provided the New World with religious sculptures. Some of these works were made at specific requests of the religious institutions of America, others were made to be sold in the American market and some of them were made using mass production techniques.

\section{Keyword}

Seville, America, XVIth century, sculpture reproduction, workshops 
Desde el Puerto de Sevilla se cargaron anualmente muchos objetos que podríamos clasificar como "artísticos" y que crecieron exponencialmente tras el descubrimiento de América. Como bien investigó López Martínez, se ha atestiguado este tráfico de obras no sólo de escultura y pintura sino también de cerámica e incluso paños.

Según la documentación, las obras escultóricas han sido muy variadas y de temática y dimensiones diferentes, aunque casi exclusivamente limitadas al campo de la imaginería. Retablos con sus arquitecturas, imágenes de bulto redondo y relieves, imágenes procesionales y de devoción particular, etc., fueron la mayoría de las piezas que se enviaron a América. Aunque más adelante se realizará algún sepulcro, fuente o estatuas con temática mitológica o profana, siempre tendrán un carácter muy minoritario ${ }^{2}$. La mayoría de esta obra fue realizada en madera, aunque también consta la existencia de algunas imágenes en otros materiales moldeables como el barro, la cera o la pasta de papel o incluso en piedra, aunque esto último fue menos común.

La temática religiosa en dichas esculturas, ligada al movimiento evangelizador que se desplegó en América y a las nuevas pautas impulsadas por el Concilio de Trento, fue muy variada: Vírgenes con Niño, Cristos en distintos momentos pasionales (por supuesto crucificados) $^{3}$, Niños Jesús ${ }^{4}$ (una iconografía en auge post-tridentino) y un gran repertorio de santos.

Fruto de este proceso evangelizador en América surgieron numerosas iglesias, capillas o ermitas que hubo de decorar ${ }^{5}$. A esto unimos la proliferación de conventos y monasterios en las grandes ciudades donde las órdenes establecían su sede y la creación de colegios. Por ello, se necesitaron grandes cantidades de esculturas y retablos para "amueblar" estas sedes, sin hablar de los hospitales y hermandades que por supuesto también requirieron de la creación de sus imágenes titulares con sus con sus respectivos retablos ${ }^{7}$. En lo que a escultura respecta, hay que reseñar que aparte de la de origen sevillano, hubo otros focos importantes como el italiano o el castellano, que también influyeron en la plástica americana, aunque sin duda los talleres de nuestra ciudad tuvieron un papel fundamental.

No es de extrañar este papel preeminente de los talleres sevillanos en las nuevas tierras conquistadas, debido principalmente a la centralización en esta ciudad del comercio con las Indias y la salida de barcos por el río Guadalquivir. Emilio Harth-Terré nos comenta que, de la gran cantidad de escultores provenientes de España durante el XVI que llegaron al Perú, una gran parte eran sevillanos (como por ejemplo Cristóbal de Ojeda que llegó en 1555 y falleció en Lima en 1578) o al menos casi todos embarcaron desde Sevilla ${ }^{8}$.

También interesante es el papel pedagógico que tuvieron algunos de estos artistas como Matías de la Cerda "español, notable esc ultor, que venido de España muy a principio de la

\footnotetext{
${ }^{1}$ En el Archivo de Protocolos Notariales de Sevilla o en el Archivo General de Indias

2 Interesante es por ejemplo el encargo a Marcos de Cabrera de tres escudos de piedra "que tiene hecho para las Yndias” en 1596. Amador Marrero/Pérez Morales, 2007-2008: 87-98.

3 Yapresentamos este Crucificado que se encuentra en la sala capitular de la antigua Universidad de San Marcos de Lima, obra probable sevillana del 20 tercio del XVI y estilísticamente cercanas a obras como el Crucificado de Almensilla o el Cristo de la Salud de Écija. Porres Benavides, 2014: 182

4 Tenemos por ejemplo la noticia de que Pedro Cano de Casaus envía a Cartagena de Indias "cuatro figuras del niño Jesús y una figura de nuestra señora de peltre" o Gaspar Luis "tres dozenas de figuritas de azabache" a la misma ciudad. Quintana Echeverría, 2000: 105.

${ }^{5}$ Es interesante el testimonio que hace Francisco Gómez de Marro, natural de Ciudad Rodrigo y residente "más tiempo de catorce años" en las provincias del Perú, a propósito de la falta de maestros de imaginería en aquellas tierras comentaba en 1553: "en aquellas provincias no hay las dichas imágenes sino las que de España se llevan, las cuales son muy caras y hacen mucha costa y no pueden ser habidas...”. Sánchez Sánchez, 2013: 189

${ }^{6}$ Es interesante como también exportaron imágenes con las devociones locales como la Virgen de la Antigua, en ocasiones, de mano de pintores de primera fila como Alejo Fernández, Sturmio y Pedro de Campaña. Sánchez Sánchez, 2013: 194. A propósito del tema de la influencia que tuvieron las hermandades sevillanas en las americanas véase Bernales Ballesteros, 1986: 51-80

7 Porres Benavides, 2014: 182

8 En esta época es interesante cómo los gremios artísticos sevillanos intentan bloquear estas relaciones con América, defendiendo la exclusividad y monopolio de estos negocios, aunque en legalidad este monopolio no existía. Así se explica el progresivo empobrecimiento de estos talleres en el XVIII cuando se traslada la Casa de Contratación a Cádiz.
} 


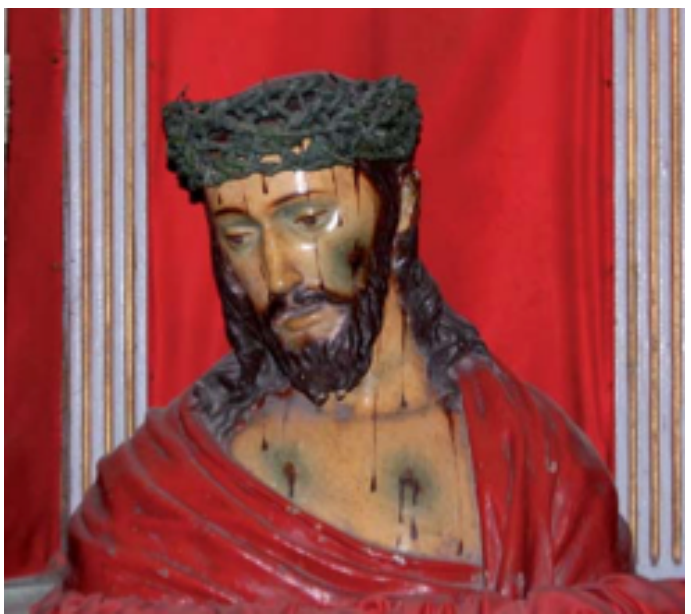

Fig. 1. Busto de Ecce-Homo. Autor anónimo sevillano. Siglo XVI. Sacristía de la iglesia de Santo Domingo de Lima.

conquista fue el primero que enseño su arte a los tarascos y la aplicación a las estatuas religiosas"'?.

El tradicional taller de escultura de carácter básicamente familiar regentado por un maestro junto a algún que otro aprendiz, se verá suplantado ahora por grandes talleres con un alto número de oficiales y aprendices para poder producir a gran escala ${ }^{10}$. Se produce la aparición de "compañías" por las cuales algunos artistas se asociaban (por lo general temporalmente) para poder abarcar más encargos. Como plantea el profesor Sánchez, hay que preguntarse si dentro de este sistema de compañías sevillanas realmente se dieron obras individualizadas o habría que hablar de obras colectivas ejecutadas con una técnica y un sistema casi artesanal. Es en estos talleres donde la atribución a tal o cual artista plantea serios problemas $^{11}$.

En la ciudad convivieron dos niveles de producción, uno de gran calidad técnica y mayor coste y otro "con ciertas notas de seriación, con destino preferente al mercado colonial y cuyo objetivo era cubrir los pedidos - siempre muy cuantiosos- realizados por los mercaderes americanos" ${ }^{\prime 2}$. Estas producciones se solían hacer en los mismos talleres y fueron dirigidas por los mismos maestros, aunque en el segundo caso intervinieran más los aprendices y oficiales y el maestro actuase al final para perfilar algún detalle o practicar algún retoque. Como explica Sánchez esta producción de obras estuvo condicionada por tres factores:

- En primer lugar por la cantidad de obras demandadas y la premura exigida para su ejecución.

- En segundo lugar por los precios que se pagaban, generalmente bajos, debido a los gastos de embarque y al beneficio que requerían los mediadores

- En tercer lugar por el bajo nivel de exigencia requerido porla clientela que los demandaba, donde noimportabademasiado "la calidaddela obra, ni siquiera el artista quelas realizaba sino que simplemente fueran "devotas ${ }^{13}$

Todo no eran ventajas, pues en estas relaciones podía haber clientes morosos difíciles de cobrar y peligros en los envíos como hundimientos o ataques de piratas a las flotas. Todo esto se fue corrigiendo mediante precauciones de "riesgos" a la hora de realizar los contratos. Estas obras ejecutadas para el comercio de ultramar casi nunca aparecen firmadas ni

9 Amador Marrero/Pérez Morales, 2007-2008: 97. 10 Sánchez Sánchez, 2013:178.

10 Sánchez Sánchez, 2013:178

${ }^{11}$ Ibídem. p. 182

12 Ibídem. p. 183

13 Ibídem. Así es interesante la descripción de las clausulas cuando Marcos de Mendiola, vecino de San Francisco de Quito, encarga a Bautista Vázquez una imagen de la Vi rgen con el Niño: la Virgen tendría "el rostro muy hermoso y graue y alegre, con un niño en brasos que sea lindo y muy alegre, y el rostro de la ymagen inclinado a mirar todas partes". 
Fig. 2. Busto de Ecce-Homo. Autor anónimo sevillano. Siglo XVI. Convento de Santo Domingo el antiguo de Toledo.

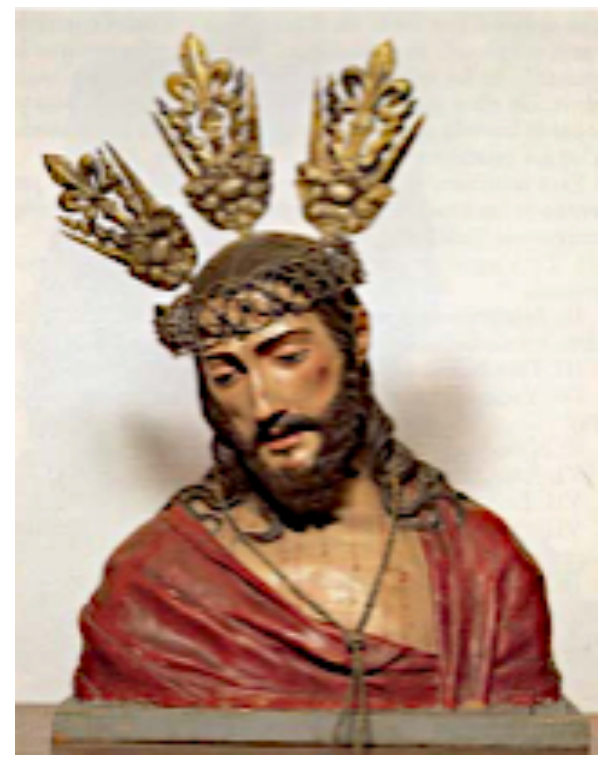

fechadas $^{14}$, ya que al comitente no le preocupaban por lo general estos datos ${ }^{15}$. Para la comercialización era frecuente que los artistas entraran en contacto con marinos o mercaderes y que estos intentaran su venta "a los mejores precios que pudieren haber o hallar".

De la actividad comercial de algunos artistas como Vázquez "el Viejo" tenemos constancia documental. Este artista se dedicó al comercio de ropas al poco de llegar a

Sevilla y es lógico que ello "le llevara a hacer lo propio con las obras de arte"16. Así, junto a encargos que le vienen del continente americano, Vázquez realiza por su cuenta imágenes devocionales para venderlas libremente y al mejor postor en aquellas tierras ${ }^{17}$. Uno de los discípulos de Vázquez, Gaspar Núñez Delgado, también enviará obras a América como conocemos por la documentación existente ${ }^{18}$. Este tipo de actividad comercial es anterior y tiene su origen en los primeros tiempos del Descubrimiento de América. Conocemos por ejemplo, que en 1519 la Casa de Contratación compró a Jorge Fernández, seis imágenes que con seguridad irían hacia América ${ }^{19}$.

Interesante es la confección de imágenes por parte de los artistas indígenas, como muestra la Nueva crónica y buen gobierno de Huamán Poma de Ayala ${ }^{20}$. Estas imágenes sobre todo se realizaron en materiales moldeables como la pasta de caña y curiosamente tuvieron también éxito en la península a donde llegaron numerosos ejemplares.

\section{La producción seriada de imágenes}

Como ya hemos comentado anteriormente, este tráfico de obras artísticas conllevó la exportación de obras de carácter devocional y de imágenes de pequeño tamaño, de carácter seriado y producción casi industrial. Mediante moldes de yeso o cola orgánica era posible la realización de múltiples vaciados en barro que luego se cocían.

Las técnicas de modelado, aunque fueron consideradas inferiores en lo que refiere a nobleza de material, eran más baratas y generalmente se utilizaban como técnicas de apoyo usadas para la realización de modelos, estudios de anatomía y ropajes. El barro cocido fue un

\footnotetext{
${ }^{14}$ Con raras excepciones, como una Inmaculada en la catedral de Oruro (Bolivia) que firma Montañez en una cartela metálica en la peana. Hernández Díaz, 1987: 247

15 Sánchez Sánchez, 2013: 1986

16 Palomero Páramo, 1988: 898.

17 Ídem

18 Un escultor que sabemos que se dedicó entre otras labores a la producción seriada de bustos de Ecce-Homo

19 Angulo Íñiguez, 1935: 21

${ }^{20}$ Gómez Piñol, 1999: 89
} 


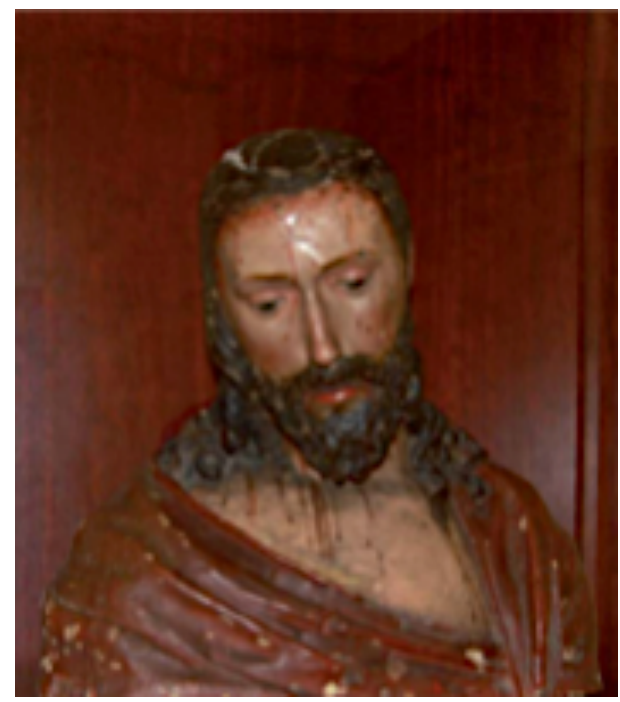

Fig. 3. Busto de Ecce-Homo. Autor anónimo sevillano. Siglo XVI. Dependencias de la hermandad de San Esteban de Sevilla.

material muy utilizado durante el Renacimiento, como podemos ver en los trabajos de las portadas de la catedral sevillana o los que el propio Juan de Juni realizó en Castilla, pero que pierde importancia en los primeros años del Barroco. Este material tuvo especial importancia para la realización de obras seriadas en la península ${ }^{21}$, aunque también se realizaron vaciados en pasta ${ }^{22}$, y en plomo. Sabemos que con destino a Centroamérica se embarcaron desde Sevilla entre 1589 y 1591 muchas imágenes de pasta ${ }^{23}$. Aparte del plomo, también se utilizaron otros metales como bronce o latón ${ }^{24}$.

En Sevilla disponemos de abundantes noticias de las labores de reproducción seriada. Así en 1574 Francisco Ramos, pintor de imaginería e impresor de ellas "se obligaba a enseñar a Cristóbal Gómez Sarabia", residente en Sevilla pero oriundo de Lima al "vaciado de medio relieve e bulto entero e de pasta yeso y tierra e pintarlo al temple e barniçarlo". En otra de las cláusulas del contrato de aprendizaje se obligaba "a daros un modelo de cada suerte para sacar hembras", es decir, un modelo para posteriormente poder realizarle un molde y reproducirlo. Más específica es todavía la anotación que recoge López Martínez acerca de la profesión de Diego Oliver, que en 1629 declaraba ser "maestro vaciador de niños de plomo" 25 .

Ya presentamos un busto de Ecce Homo (fig. 1) que se encuentra en un retablo de la sacristía de la iglesia de Santo Domingo de Lima, de origen sevillano. Es un vaciado del mismo molde de otros Ecce Homo, como el de la cofradía sevillana del Cristo de la Salud y

21 Así sabemos que en 1610, Bernabé de Baeza embarcó rumbo a América "seiscientos crucificados de barro cocido, doscientos "grandes, de cuarta y media" (32 cm aprox.), otros doscientos "un poco menos de una cuarta" (21 cm. aprox.) y los doscientos restantes de "poco menos de una cuarta" (unos $18 \mathrm{~cm}$.)

22 Generalmente en pasta de papel, que se llamaban popularmente de "papelón”. La existencia de este tipo de piezas se relaciona, como bien nos indica Gómez Piñol al hablar de la imaginería sevillana del XVI, con su bajo coste y en especial por el carácter procesional de las mismas.

23 Generalmente en pasta de papel, que se llamaban popularmente de "papelón”. La existencia de este tipo de piezas se relaciona, como bien nos indica Gómez Piñol al hablar de la imaginería sevillana del XVI, con su bajo coste y en especial por el carácter procesional de las mismas.

${ }^{24}$ Deben recordarse las tres mil imágenes en estos materiales que se enviaron a México entre los años de 1592 a 1594. Ibídem, p. 523

${ }^{25}$ López Martínez, 1928: 106. Sobre este tema se puede consultar el artículo de Palomero Páramo, 2007:105-114. 


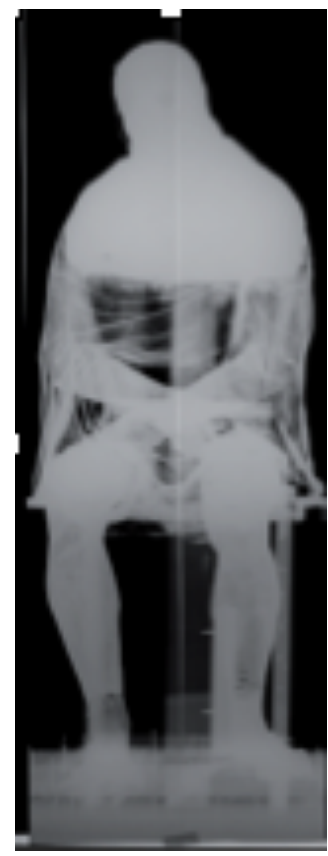

Fig. 4. Radiografia del Santíimo Cristo de la Salud y Buen Viaje. Hermandad de San Esteban. (C) Instituto Andaluz del Patrimonio Histórico. Eugenio Fernández Ruiz. Sevilla.

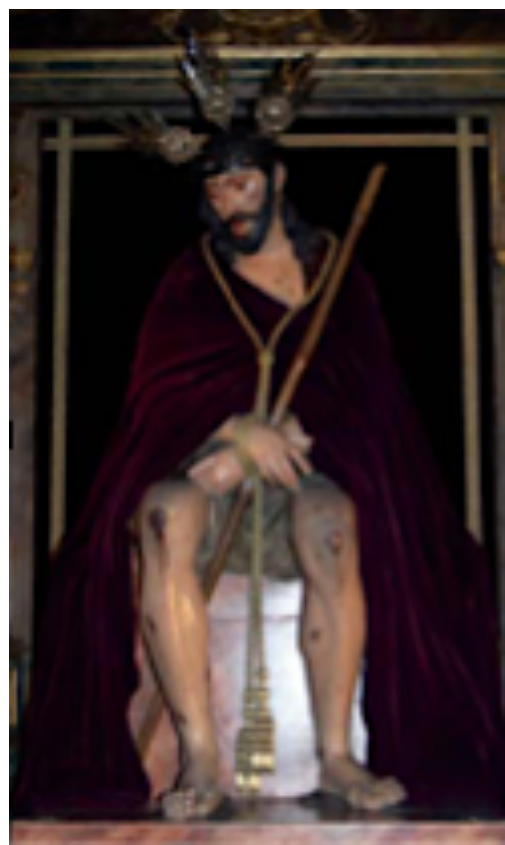

Fig. 5. Santísimo Cristo de la Saludy Buen Viaje. Hermandad de San Esteban. Sevilla.

Buen Viaje ${ }^{26}$ o el que se conserva en el convento de Santo Domingo "el antiguo" de Toledo (fig. 2) proveniente a su vez del convento sevillano de Dueñas ${ }^{27}$. Se trata de una pieza de unos $35 \mathrm{~cm}$ de alto por $35 \mathrm{~cm}$. de ancho por 25 de profundidad, que aunque repolicromado todavía conserva una gran belleza ${ }^{28}$. Con éste serían ya cinco los ejemplares que se conocen, pues hay que sumar uno en poder de la hermandad comprado hace unos años al anticuario Antonio Plata de Sevilla (fig. 3) y otro en la iglesia parroquial de Santa Maria de las Nieves de La Campana (Sevilla) ${ }^{29}$.

Para la ocasión se ha podido estudiar esta última ${ }^{30}$, y se observa, a pesar del deficiente estado de conservación, que es muy parecida de los ejemplares de Toledo y Perú (este último repolicromado posteriormente lo que altera algo su estado original), con disposición de la túnica y que son vaciados que pudieron salir del mismo molde. El de la hermandad tiene unas grapas metálicas antiguas en la zona del pecho (anverso y reverso) para "coser" la imagen, que se pudo partir después de la cocción o en un momento posterior. La imagen de la Salud y Buen Viaje y la de Toledo comparten unos añadidos de estopa y yeso en los cabellos laterales en forma de mechones rizados (puestos quizás en alguna restauración posterior), que la dotan de cierta plasticidad.

${ }^{26}$ La devoción a la imagen de Jesús de la Salud y el Buen Viaje se originó en la plegaria de los arrieros que salían de Sevilla por la Puerta de la Carne. Según recientes investigaciones, la imagen del Señor perteneció a una antigua congregación, llamada de la Anunciata, que estuvo establecida en una capilla del Colegio de San Hermenegildo de la Compañía de Jesús. Después fue llevada a la iglesia de San Esteban en el año 1772, cuando fue certificada por el visitador Pedro de Castilla. Amores Martínez, 2003: 104. Además para profundizar más acerca de dicha imagen, recientemente se han publicado sendos artículos Amores Martínez, 2015: 183-186 y Ruiz Copete, 2015

27 El de Toledo viene del convento de las Dueñas de Sevilla, tras la exclaustración. De hecho aparece en un inventario de bienes que se llevan al convento de Toledo como "un Ecce Homo grande". Fraga Iribarne, 1993: 174.

28 Sánchez Sánchez, 2013: 182.

29 Amores Martínez, 2015: 184

${ }^{30}$ Que tiene unas medidas de 38 (alt.) x 39 (anch) x 18 (prof.) cm. 


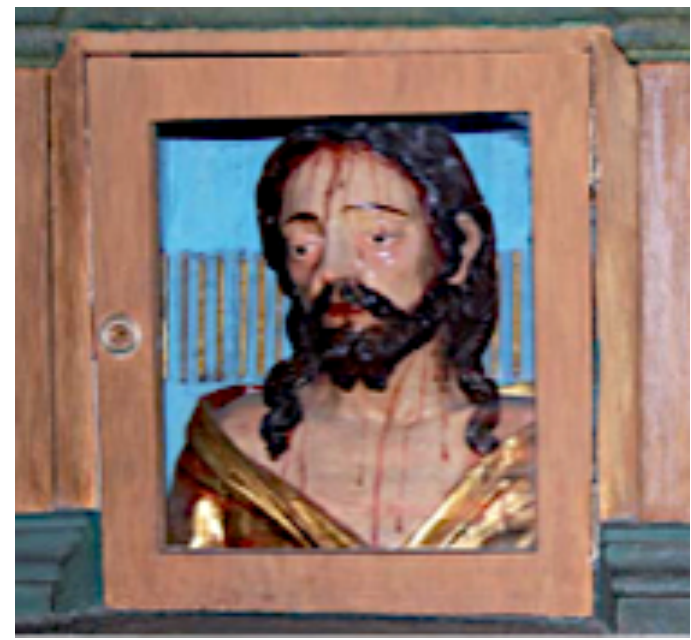

Fig. 6. Busto de Ecce-Homo. Autor anónimo sevillano. Siglo XVI. Escalera del convento de San Francisco de Lima

El Cristo de la Salud y Buen Viaje originariamente era sólo un busto modelado en barro ${ }^{31}$ y que podría datarse a principios del siglo XVI. Posteriormente quizás a su traslado a San Esteban se le incorporó el cuerpo de madera tallada al busto (fig.4) realizado en barro cocido (fig.5), excepto su pie izquierdo que también se modeló en terracota y se incorporaron las cinco lágrimas que tiene en el rostro.

En América sabemos que gustó siempre este tipo de imágenes devocionales y que existió un tráfico de Ecce Homos ${ }^{32}$, llegando magníficos ejemplos de piezas como los bustos de Dolorosa y Ecce Homo de Pedro de Mena, conservados en la iglesia de San Pedro de Lima. Sirva de ejemplo un protocolo de 1584 donde el mercader Antonio de Aranda declaró que debía a Juan de Chacón, pintor de imaginería, 24 ducados por razón de "seis Ecce-homo de medio relieve de bulto que me habéis vendido"33.

${ }^{31}$ Y así se describe en el inventario que se hace de la iglesia: "Un busto de $1 / 2$ cuerpo on su peana dorada de un Ecce homo con su corona de espinas y soga al cuello — del que se dice después— que era grande y de barro”. Amores Martínez, 2003: 104

32 Así por ejemplo consta por documentos del archivo franciscano de Quito que en 1756 se remitieron a Lima "cabezas y manos de nuestra señora de los dolores, el señor ecce homo, san joan" etc. Gento Sanz, 1945: 47. De época algo posterior se puede citar también un busto de Ecce Homo conservado en una hornacina de un pequeño retablo que se ubica en el rellano de la escalera principal del convento de San Francisco de Lima (fig.6). También se puede relacionar con la escuela sevillana y en concreto con la producción de los discípulos de Martínez Montañez como Gaspar de la Cueva u Ocampo

33 López Martínez, 1929: 178. 
Bibliografía

Amador Marrero, P. y Pérez Morales, J.: "El sevillano “capitán" Marcos de Cabrera: personaje enigmático, notable escultor. Revisión histórico-artística y técnica". Atrio 13 y 14, (2007-2008), pp. 87-98.

Amores Martínez, F.: "La Compañía de Jesús y las hermandades de Sevilla. Noticias histórico-artísticas". En: Roda Peña, J. (dir.): Actas del IV Simposio sobre hermandades de Sevilla y su provincia, Sevilla, Fundación Cruzcampo, (2003), pp. 87-128.

Amores Martínez, F.: "Las lágrimas del Señor de la Salud y Buen Viaje". Boletín de las Cofradías de Sevilla. Año LIV- 673, Sevilla, (2015), pp. 183-189,

Angulo Iñiguez, D.: "Dos Menas en Méjico. Esculturas sevillanas", Archivo español de Arte y Arqueología (11): 31, (1935), pp. 131-152.

Bernales Ballesteros, J.: "Escultura montañesina en América", Anuario de estudios americanos, (1981), pp.

499-566.

Fraga Iribarne, $\mathrm{M}^{\mathrm{a}}$ L.: Conventos femeninos desaparecidos. Sevilla -Siglo XIX. Ediciones Guadalquivir, Sevilla, (1993).

Gento Sanz, B.: San Francisco de Lima. Estudio histórico y artístico de la iglesia y convento de San Francisco de Lima. Lima. (1945).

Hernández Díaz, J.: Juan Martinez Montañés (1568-1649), Sevilla: Ediciones Guadalquivir, (1987) López Martínez, C.: Retablos y esculturas, Sevilla, .Imp. Rodríguez Giménez.(1987).

López Martínez, C.: Desde Martínez. Montañés hasta Pedro Roldán, Sevilla, Imp. Rodríguez Giménez. (1929).

Palomero Páramo, J:: "Juan Bautista Vázquez, el viejo, mercader de arte y ropa con Indias". Aportaciones biográficas y artísticas en su IV centenario", Archivo Ibero-Americano, Año no 48, 189-192, Ejemplar dedicado a: Los Franciscanos y el nuevo mundo. II congreso internacional. La Rábida, (1988), pp. 895-903.

Palomero Páramo, J.: "El mercado escultórico entre Sevilla y Nueva España durante el primer cuarto del siglo

XVII. Marchantes de la carrera de Indias, obras de plomo exportadas y ensambladores de retablos que pasan a México", Escultura. Museo Nacional del Virreinato, Asociación de Amigos del Museo Nacional del Virreinato, México, (2007): pp. 105-109.

Porres Benavides, J.: "Bautista Vázquez "el Viejo" y su escuela en los antecedentes del Barroco Hispanoamericano" en Actas del congreso internacional del Barroco. Arica 2013. Edit. en La Paz- Bolivia. (2014): pp. 181-192.

Quintana Echeverria; I.: "Notas sobre el comercio artístico entre Sevilla y América en 1586", Anales del Museo de América, (2000), pp. 103-110

Recio Mir, A.: "La difusión de los modelos montañesinos del Niño Jesús: causas de una producción seriada" en Ramos Sosa, R. (Coor.) Actas del coloquio internacional el Niño Jesús y la infancia en las artes plásticas, siglos XV al XVII. IV centenario del Niño Jesús del sagrario, 1606-2006, Sevilla, (2010), pp. 261-288.

Ruiz Copete, A.M.: "Origen, fundación y primeros años de la hermandad de San Esteban" Boletin de las cofradias de Sevilla. Año LIV- 673, (2015): pp 176-182.

Sánchez Sánchez, J.M.: "Los obradores artísticos sevillanos del siglo XVI: adaptaciones y cambios para satisfacer los encargos del mercado americano" Anales del Instituto de Investigaciones Estéticas XXXV (103). Méjico. (2013), pp. 177-196.

Sancho Corbacho, H.: "Contribución documental al estudio del arte sevillano" en tomo II de Documentos para la historia del arte en Andalucía. Sevilla. (1928), pp. 240-260. 